\title{
Endoscopic ultrasound-guided gallbladder drainage as a strategy to overcome shortage of operating rooms and intensive care unit beds during Covid-19 crisis
}

The Covid-19 outbreak has induced dramatic changes to health care in Italy. Restrictions to intensive care units (ICU) and operating rooms to care for Covid19 patients has limited the facilities available for infection-free patients [1,2]. We report on a patient with sepsis due to acute cholecystitis who was managed entirely outside the operating room and ICU.

An 80-year-old woman who had been admitted to a rehabilitation institute 20 days earlier following a spinal injury, developed sepsis. Liver enzymes (aspartate aminotransferase $89 \mathrm{U} / \mathrm{L}$ ), white blood cells $\left(27000 / \mathrm{mm}^{3}\right)$, bilirubin $(2.9 \mathrm{mg} / \mathrm{dL})$, and C-reactive protein $(37.2 \mathrm{mg} / \mathrm{dL})$ were markedly elevated. Her condition worsened overnight and she was referred to hospital. Computed tomography showed marked dilation of the gallbladder with thickened walls and multiple radio-opaque stones. Additionally, complete collapse of the left lung and findings suspicious for Covid-related pneumonia were reported ( $>$ Fig. $\mathbf{1}$ ). As ICU was unavailable, and following multidisciplinary evaluation, she was moved to the endoscopy suite for drainage. Pending Covid-19 results, she was managed as a positive case as a precaution (i.e. negative-pressure room, personal protective equipment) ( $\mathbf{F i g . ~} \mathbf{2}$ ).

Endoscopic ultrasound-guided gallbladder drainage (EUS-GBD) was preferred over percutaneous drainage to allow definitive treatment and, potentially, rapid discharge from hospital [3-5]. EUS-GBD was achieved by placement of a 10-mm electrocautery-enhanced lumenapposing metal stent ( $\mathbf{F i g . 3 , ~}$ Fig.4, - Video 1). The procedure lasted $20 \mathrm{~min}$ utes and was conducted under deep sedation. The patient experienced prompt reduction of abdominal pain and remained afebrile. No complications developed and she was discharged 4 hours later. She resumed oral feeding the fol-
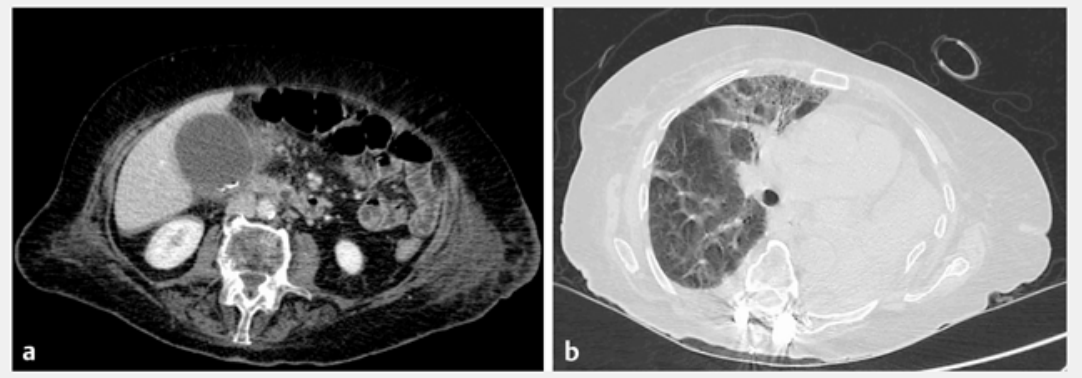

- Fig. 1 Computed tomography images. a Markedly dilated gallbladder, with thickened wall and small stones. $\mathbf{b}$ Collapsed left lung and signs of diffuse pneumonia with ground-glass areas in the right lung.

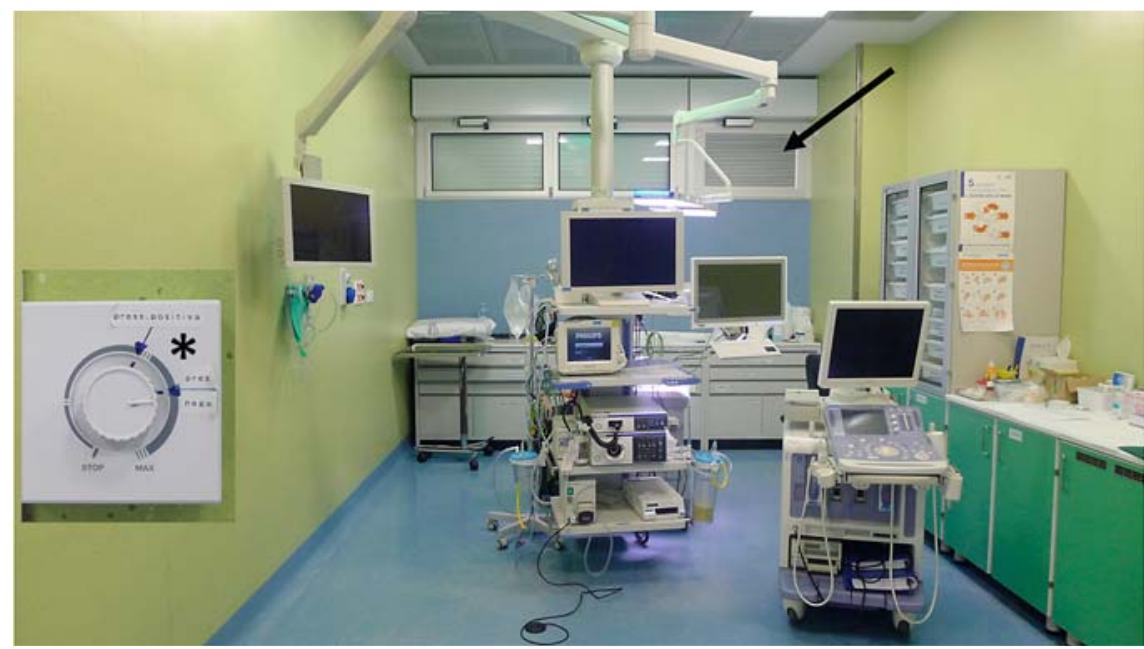

Fig. 2 Endoscopy room with a dedicated ventilation system (black arrow) to guarantee a negative pressure (asterisk).

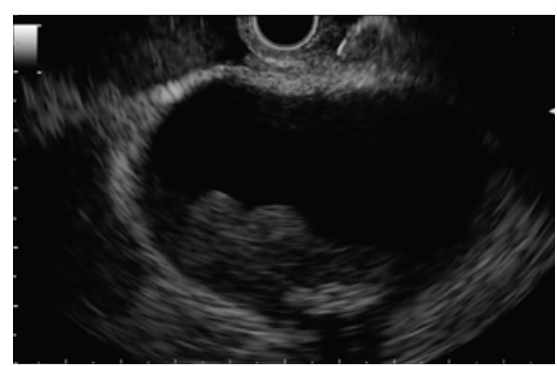

-Fig. 3 Endoscopic ultrasound image of the gallbladder from the duodenal bulb.

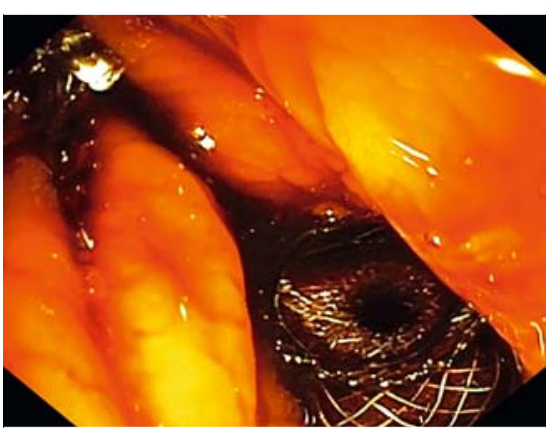

- Fig. 4 Proximal (duodenal) flange after complete release of the lumen-apposing metal stent. 


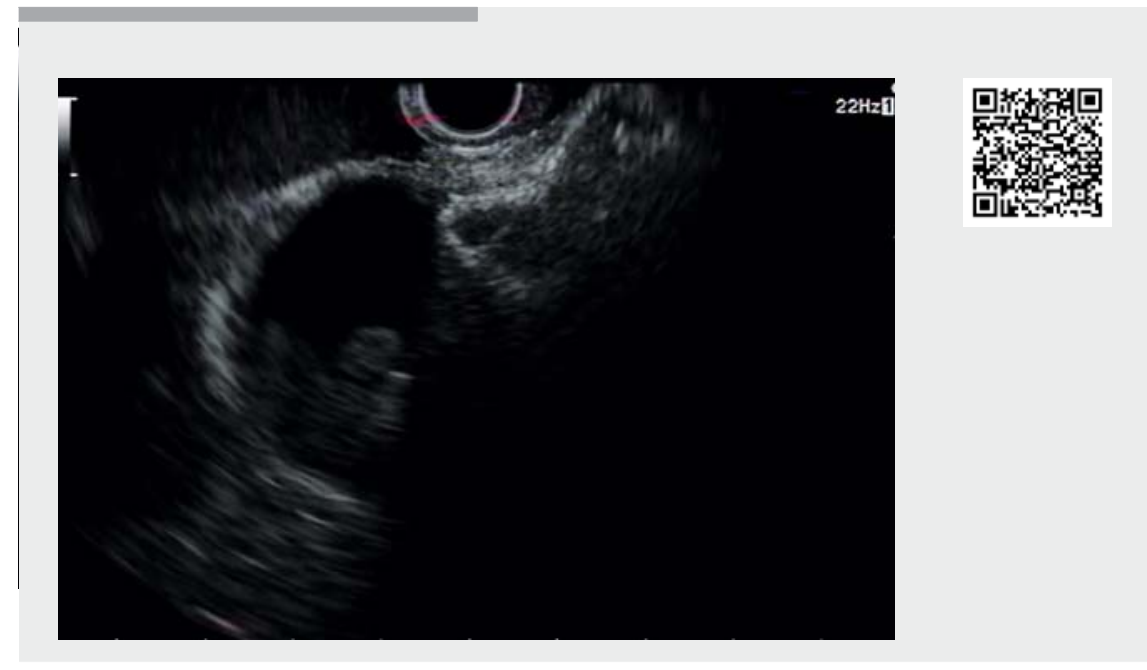

$\checkmark$ Video 1 Endoscopic ultrasound-guided gallbladder drainage in an 80-year-old patient with suspected Covid-19 infection.

lowing day, and biochemical abnormalities started to return to normal.

EUS-GBD is established for acute cholecystitis in high-risk surgical patients. During the Covid-19 crisis, indications for this minimally invasive treatment may expand in order to avoid more resource-consuming interventions such as surgery and intensive care admissions.

Endoscopy_UCTN_Code_TTT_1AS_2AD

\section{Competing interests}

The authors declare that they have no conflict of interest.

The authors

\footnotetext{
Andrea Lisotti ${ }^{1,2}$, Igor Bacchilega ${ }^{3}$, Romano Linguerri ${ }^{4}$, Pietro Fusaroli ${ }^{1,2}$

1 Gastroenterology Unit, Hospital of Imola, Imola, Italy

2 Department of Medical and Surgical Sciences - DIMEC, University of Bologna, Bologna, Italy

3 Intensive Care Unit, Hospital of Imola, Imola, Italy

4 Surgery Unit, Hospital of Imola, Imola, Italy
}

[4] Fabbri C, Luigiano C, Lisotti A et al. Endoscopic ultrasound-guided treatments: are we getting evidence based - a systematic review. World J Gastroenterol 2014; 20: 8424-8448

[5] Fusaroli P, Serrani M, Sferrazza S et al. Elective cholecystectomy after reversal of septic shock using multimodality endoscopic gallbladder drainage. Endoscopy 2018; 50 : E299-E300

\section{Bibliography}

DOI https://doi.org/10.1055/a-1158-9102

Published online: 6.5.2020

Endoscopy 2020; 52: E263-E264

(c) Georg Thieme Verlag KG

Stuttgart · New York

ISSN 0013-726X

\section{ENDOSCOPY E-VIDEOS}

https:|/eref.thieme.de/e-videos

\section{Pietro Fusaroli, MD}

Gastroenterology Unit, Hospital of Imola, Department of Medical and Surgical Science, University of Bologna, Via Montericco 4, 40026 Imola (BO), Italy

Fax: +39-054-2662409

pietro.fusaroli@unibo.it

\section{References}

[1] Grasselli G, Pesenti A, Cecconi M. Critical care utilization for the COVID-19 outbreak in Lombardy, Italy: early experience and forecast during an emergency response. JAMA 2020. doi:10.1001/jama.2020.4031

[2] Buscarini E, Conte D, Cannizzaro R et al.; Italian Association of Hospital Gastroenterologists and Endoscopists (AIGO), Italian Society of Endoscopy (SIED), Italian Society of Gastroenterology (SIGE). White paper of Italian Gastroenterology. Delivery of services for digestive diseases in Italy: weaknesses and strengths. Dig Liver Dis 2014; 46: 579-589

[3] Fusaroli P, Jenssen C, Hocke M et al. EFSUMB guidelines on interventional ultrasound (INVUS), Part V - EUS-guided therapeutic interventions (short version). Ultraschall Med 2016; 37: 412-420 